\title{
Características da fase aguda da avulsão do nervo óptico pós-trauma: relato de caso
}

\author{
Acute post-traumatic optic nerve a vulsion:case report
}

\author{
Magno Antônio Ferreira ${ }^{1}$ \\ Cristiano Toesca Espinhosa ${ }^{2}$ \\ Eduardo Guilherme Vaz Andreo ${ }^{3}$ \\ Ioná Guedes Alves Finotti ${ }^{4}$ \\ Leonardo Bruno de Oliveira ${ }^{5}$
}

\section{RESUMO}

A avulsão do nervo óptico representa uma entidade rara, levando a resultados devastadores na maioria dos casos e com prognóstico reservado. A presença de meios translúcidos possibilita, na maioria das vezes, diagnósticos acurados, mostrando a fundoscopia tipicamente uma cavidade localizada no local da retração do disco óptico para sua bainha dural. Embora exames complementares raramente sejam necessários para o diagnóstico desta afecção, quadros clínicos associados a graus variados de turvação de meios dióptricos e algum grau residual da visão, como nas roturas parciais, podem levar à dificuldade do diagnóstico e mesmo retardar o processo terapêutico. Neste artigo, relatamos a fase aguda de um caso típico de avulsão completa do nervo óptico, examinado no Serviço de Retina e Vítreo do Hospital de Clínicas da Universidade Federal de Uberlândia - MG.

Descritores: Traumatismo do nervo óptico/diagnóstico; Hemorragia retiniana; Traumatismos oculares; Hemorragia vítrea; Tomografia computadorizada por raios x; Relatos de casos [Tipo de publicação]

\section{INTRODUÇÃO}

A descrição histológica de avulsão do nervo óptico data de $1856^{\text {(apud 3), }}$ tendo sido seu quadro clínico primeiramente relatado por Salzmann em 1903. Representa entidade rara, porém com resultado visual devastador ${ }^{(1)}$. Constitui-se de uma rotura do nervo óptico ao nível de seu disco, com retração para o canal escleral ${ }^{(2)}$.

Avulsões completas (com perda total da visão) e parciais (com algum grau residual de visão) são descritas na literatura ${ }^{(3)}$, ambas resultando de traumas cranianos contusos ${ }^{(4)}$ ou de traumas oculares fechados. Existe, assim, compressão do globo ocular e rotação extrema do mesmo contra as paredes orbitárias ou um aumento súbito e intenso da pressão intra-ocular, forçando o nervo para fora do canal escleral ${ }^{(5)}$. A mobilidade do nervo dentro da órbita constitui fator predisponente, pois o mesmo é recoberto apenas por bainhas a este nível ${ }^{(3)}$.

A presença de meios claros possibilita um diagnóstico preciso, mostrando à fundoscopia lesão típica, com cavidade presente no local em que o disco óptico retraiu-se para sua bainha dural ${ }^{(4)}$.

Exames complementares podem ser úteis, na presença de meios turvos para a detecção da avulsão, como a tomografia computadorizada ou a ultrasonografia ocular (B-scan), entretanto, com baixas sensibilidades ${ }^{(4)}$.

Considerando a raridade do quadro clínico exposto e a inexistência de publicações na literatura nacional, relatamos um caso de avulsão traumática do nervo óptico diagnosticado durante o atendimento de urgência do Setor 
de Retina e Vítreo do Hospital das Clínicas da Universidade Federal de Uberlândia em 5 de março de 2004.

\section{RELATO DE CASO}

NNP, sexo masculino, 32 anos, deu entrada no serviço de urgência com quadro de perda súbita e total da visão em olho direito acompanhada de dor local intensa, após forte trauma ocular direto, com fragmento de madeira, há 3 horas. O paciente negava problemas oculares ou de saúde geral prévios. Ao exame apresentava em olho direito: ausência de percepção luminosa; biomicroscopia com hiperemia conjuntival moderada, córnea clara, reação de câmara anterior com "flare" discreto, cristalino transparente e pupila em meia midríase com reflexo fotomotor direto ausente (defeito pupilar aferente); tonometria de $11 \mathrm{mmHg}$. A fundoscopia evidenciou hemorragia pré-retiniana, circundando o disco óptico e em pólo posterior inferiormente, retina pálida no pólo posterior e nos quatro quadrantes alcançando a região equatorial, associado a atenuação vascular com afinamento arterial significativo, hemorragia sub-retiniana sob a arcada temporal inferior, provavelmente oriunda de rotura de coróide; nervo óptico com aspecto deprimido, não sendo observada a emergência vascular; hemorragias vítreas esparsas (Figuras 1 e 2). O olho esquerdo apresentava exame dentro dos parâmetros da normalidade.

No segundo dia pós-trauma, após terapia tópica com colírio de atropina $1,0 \%$ e colírio de dexametasona houve melhora do quadro doloroso ocular e o exame fundoscópico mostrava todas as alterações descritas acima, exceto a hemorragia subretiniana, que já havia sido reabsorvida espontaneamente.

A história clínica associada aos achados fundoscópicos revelou um quadro típico de avulsão completa do nervo óptico direito. A tomografia computadorizada de crânio e órbitas não demonstrou ocorrência de fratura óssea. $\mathrm{O}$ paciente permaneceu sob acompanhamento clínico durante uma semana em nosso serviço, sem alteração de seu exame clínico. Após este período não compareceu mais aos retornos marcados.

\section{DISCUSSÃO}

O quadro clínico de avulsão total ou parcial do nervo óptico constitui situação dramática na prática oftalmológica. Nesses casos, a acuidade visual apresenta-se inexoravelmente comprometida se o dano é total, tendo gradações variáveis se o dano é parcial, sendo descritas acuidades visuais desde ausência de percepção luminosa até valores de 20/100. O seguimento dos pacientes, mostra em geral, a preservação ou a deterioração da acuidade inicial. No caso em questão o paciente apresentava acuidade visual de ausência de percepção luminosa ${ }^{(1,6)}$ inicialmente, com tomografia computadorizada de crânio e órbita não mostrando ocorrência de fratura óssea e sendo ineficiente em demonstrar avulsão do nervo óptico. $\mathrm{Na}$ presença de meios transparentes, o diagnóstico de avulsão do nervo óptico é, em geral preciso; entretanto, a presença de meios opacos dificulta a visualização do fundo de olho e, conseqüentemente, contribui para o retardo do diagnóstico ${ }^{(6-7)}$.

Considera-se que exames complementares, como tomografia ou ultra-sonografia ocular, possuem papel restrito para o diagnóstico, pois apresentam baixas sensibilidades ${ }^{(1,7-8)}$. Uma indicação importante para a ultra-sonografia ocular é a comprovação da integridade do globo na presença de meios opacos ${ }^{(2)}$. Em alguns casos, a tomografia de órbitas pode mostrar uma lesão completa ou parcial do nervo óptico ${ }^{(9)}$, com uma área de hipolucência na junção do nervo com o globo e uma hiperlucência proximal ao globo sugestiva de deslocamento posterior da lâmina crivosa; entretanto sua eficiência está em mostrar fraturas orbitárias ou dos ossos do crânio associadas ${ }^{(4)}$.

No relato de caso aqui apresentado, observamos na fundoscopia quadro clínico compatível com avulsão do nervo óptico. O padrão fundoscópico descrito e conforme mostrado

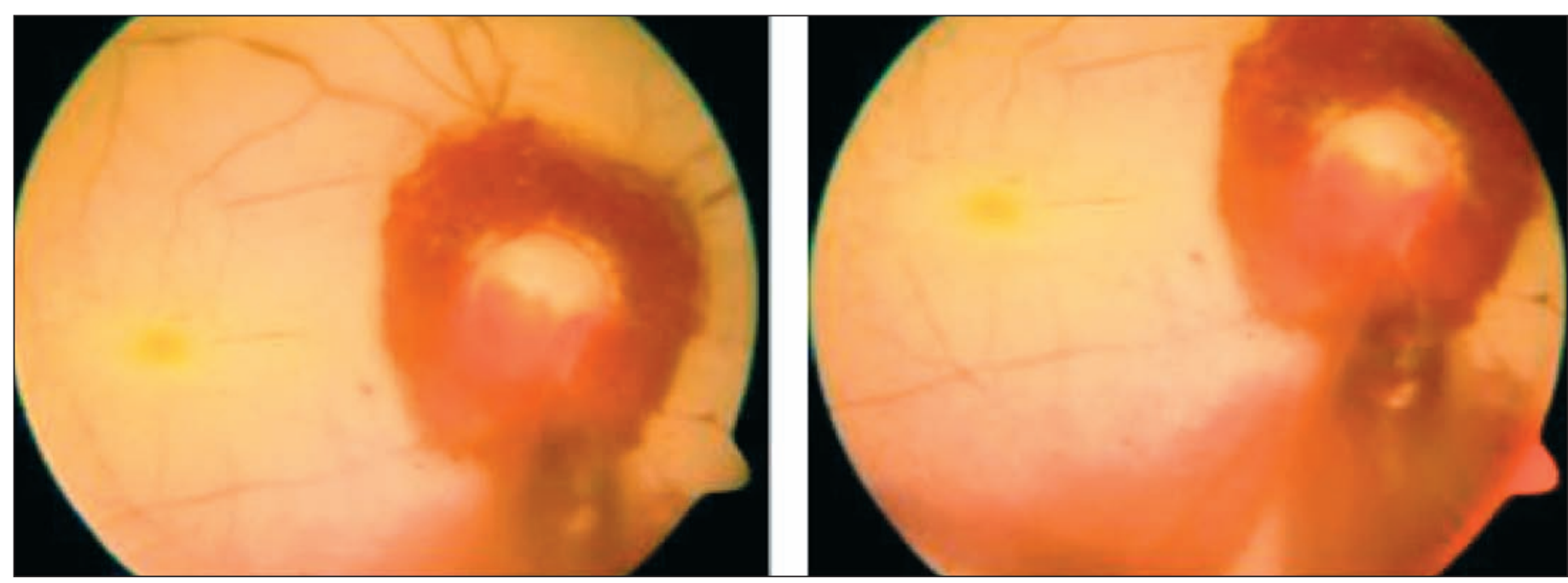

Figuras 1 e 2 - Fase aguda da avulsão do nervo óptico pós-trauma - Retinografia 
pelas figuras é correlato com as descrições da literatura; entretanto, hemorragias vítreas predominam em virtude da energia do impacto provocado pelo trauma ${ }^{(1-2,5-6)}$, ressalte-se, que esparsas neste caso em especial.

Considerando a íntima relação do nervo óptico com a vasculatura retiniana, a mesma pode se apresentar de forma variada nos casos de avulsão do nervo: desde um padrão normal, até várias alterações podem estar presentes incluindo tortuosidade, atenuação vascular, oclusão arterial ao nível da avulsão e segmentação da coluna sanguínea intravascular ${ }^{(4)}$. Neste estudo, observamos um padrão fundoscópico típico de isquemia retiniana secundária à perda de fluxo arterial, devido, provavelmente, à rotura dos vasos sanguíneos arteriais quando da retração do nervo óptico para o canal escleral.

Em conclusão, as neuropatias ópticas traumáticas, nas quais a avulsão do nervo óptico está compreendida, devem sempre ser lembradas no atendimento de pacientes vítimas de traumas oculares diretos ou cranianos graves, pois, apesar do prognóstico visual reservado e da ausência de tratamento especifico, representam ainda um desafio diagnóstico, principalmente na presença de opacidades de meios, por não haver nenhum exame complementar confiável e sensível para evidenciar a lesão.

\section{ABSTRACT}

Optic nerve avulsion is a rare, but devastating complication. In this condition, the optic nerve is forcibly disinserted from the retina, choroid, and vitreous, and the lamina cribrosa is retracted from the scleral rim. If the media are clear, the avulsion is easily diagnosed. The appearance of the fundus is striking, with a hole or cavity where the optic disc has retracted into its dural sheath. The complementary examinations are not very accurate for the diagnosis of this pathology and with some residual vision, opaque media, that occur in partial avulsion, the diagnosis may be mistaken or delayed. In this article we report a case of complete optic nerve avulsion examined at the Retina and Vitreous Department of the "Hospital das Clínicas" of the Federal University of Uberlândia - MG - Brazil.

Keywords: Optic nerve injuries/diagnosis; Retinal hemorrhage; Eye injuries; Vitreous hemorrhage; Tomography, x-ray computed; Case reports [Publication type]

\section{REFERÊNCIAS}

1. Youssri AI, Young LH. Closed-globe contusion injuries of the posterior segment. Int Ophthalmol Clin. 2002;42(3):79-86.

2. Sanborn GE, Gonder JR, Goldberg RE, Benson WE, Kessler S. Evulsion of the optic nerve: a clinicopathological study. Can J Ophthalmol. 1984;19(1):10-6.

3. Williams DF, Williams GA, Abrams GW, Jesmanowicz A, Hyde JS. Evulsion of the retina associated with optic nerve evulsion. Am J Ophthalmol. 1987;104 (1):5-9. Erratum in: Am J Ophthalmol. 1987;104(2): following 206.

4. Buchwald HJ, Spraul CW, Wagner P, Lang GK. [Optic nerve evulsion: Metaanalysis]. Klin Monatsbl Augenheilkd. 2001;218(10):635-44. German.

5. Buchwald HJ, Otte P, Lang GE. [Evulsion of the optic nerve following blunt bulbar trauma. Case report and review of the literature]. Klin Monatsbl Augenheilkd. 2003;220(5):303-8. German.

6. Foster BS, March GA, Lucarelli MJ, Samiy N, Lessell S. Optic nerve avulsion. Arch Ophthalmol. 1997;115(5):623-30. Erratum in: Arch Ophthalmol. 1997; 115(8):1070.

7. Tsopelas NV, Arvanitis PG. Avulsion of the optic nerve head after orbital trauma. Arch Ophthalmol. 1998;116(3):394.

8. Roth DB, Warman R. Optic nerve avulsion from a golfing injury. Am J Ophthalmol. 1999;128(5):657-8.

9. Roberts SP, Schaumberg DA, Thompson P. Traumatic avulsion of the optic nerve. Optom Vis Sci. 1992;69(9):721-7.

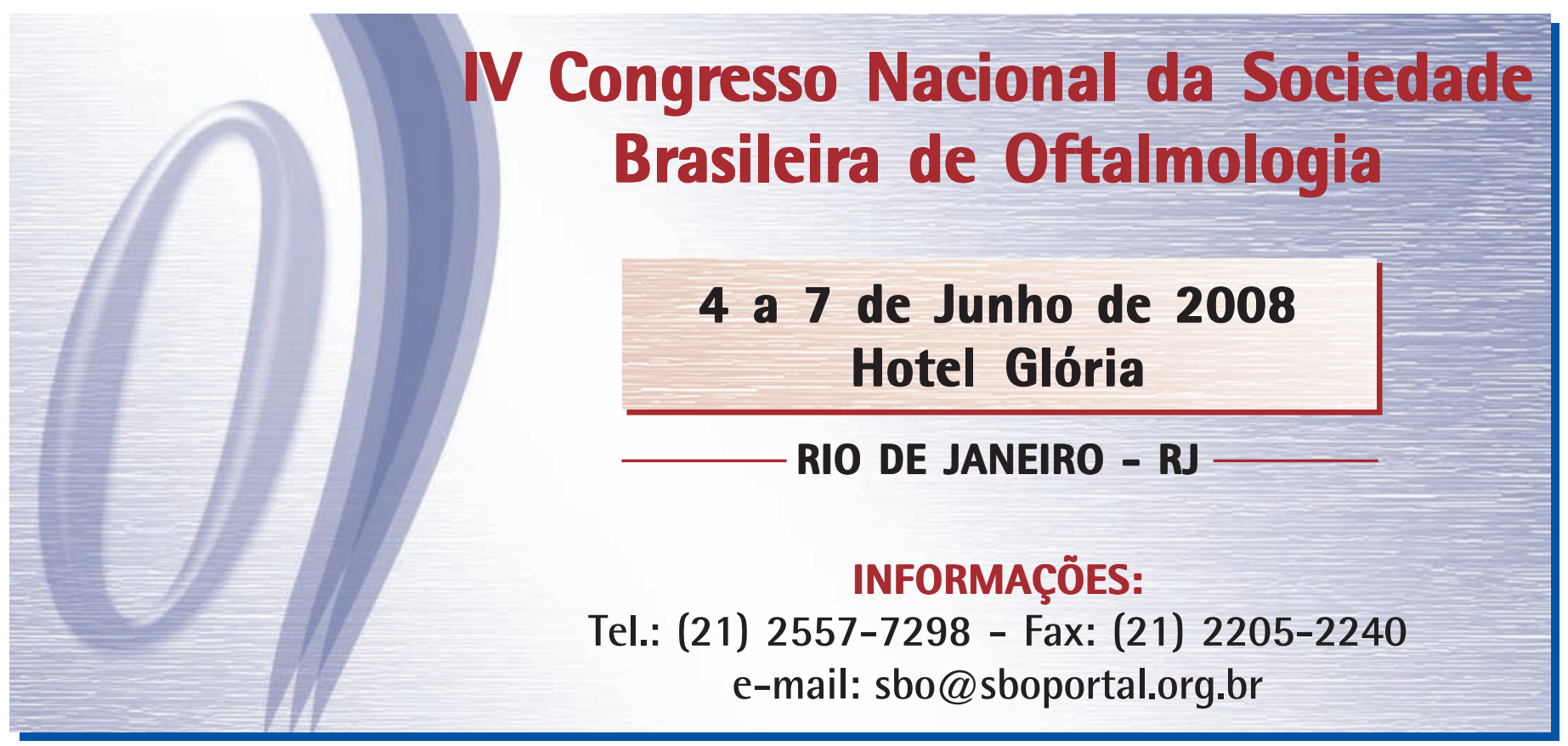

